\title{
Governance of food and nutrition security in Eswatini: an analysis of government policies and reports
}

Thobile Phungwayo', Sandra Boatemaa Kushitor ${ }^{2^{*}}$ and Liesbet Koornhof ${ }^{3}$

\begin{abstract}
Background: Governance of food and nutrition security is vital in achieving sustainable development goals. Yet, the role of governance in shaping and preventing malnutrition risk is complex and poorly understood. This paper examined the governance of food and nutrition security in Eswatini.

Methods: Policy documents, annual reports, and minutes of board meetings from five government ministries were the documents that were used for this study. The data analysis focused on the strength of nutrition governance, actors involved in policymaking, nutrition-specific and sensitive-programs, and multisectoral coordination of programs.

Results: The findings show that Eswatini has medium strength, nutrition governance. The nutrition-specific programs included: micronutrient supplementation and deworming programs, breastfeeding campaigns, and treatment of acute malnutrition. The nutrition-sensitive initiatives included programs on school nutrition, sanitation and hygiene, agriculture production, and healthcare. However, multisectoral coordination was ineffective, as collaborative efforts are not structured, during implementation.

Conclusion: This study examined the governance of food and nutrition security in Eswatini using documents from government ministries. Diverse actors were involved in policy formation and implementation. The strength of nutrition governance was medium and multisectoral coordination was usually ad-hoc. The multiple actors involved in nutrition governance in Eswatini need to intentionally plan to improve multisectoral coordination to achieve higher impact.
\end{abstract}

Keywords: Food access, Malnutrition, Nutrition interventions, Food policy, Multisectoral coordination

\section{Background}

Food and nutrition insecurity is a global challenge [1$3]$. It has been estimated that about $22 \%$ of children are stunted and about a third of adults are overweight and obese [4]. The burden of food and nutrition insecurity is higher in low and middle-income countries than highincome countries [2,5]. According to the 2018, Global

\footnotetext{
*Correspondence: boatemaa@sun.ac.za

2 Food Security Initiative and Centre for Complex Systems in Transition, Stellenbosch University, Stellenbosch, South Africa
}

Full list of author information is available at the end of the article
Nutrition Report, several countries are unable to address the multiple forms of malnutrition concurrently [4]. Food and nutrition insecurity is a major contributor to disability, diseases, economic stagnation, and impaired cognitive development [6-9]. The 2020 Global Nutrition Report, reiterated the importance of improving food and health systems to make them more equitable, resilient, and sustainable to address the needs of the most vulnerable people globally [10].

The causes of food and nutrition insecurity are multifactorial and include political, social, cultural, and economic factors, for example, poor child care practices, 
insufficient hygiene, and sanitation or health care $[4,5,8]$. The United Nations International Children's Emergency Fund (UNICEF) Framework provides an understanding of the basic, underlying and immediate causes of malnutrition [11]. In addition, the framework includes impact pathways where governance aspects are weaved into the causes of food and nutrition insecurity. The Lancet 2013 Maternal and Child Nutrition series also highlights the importance of leadership and accountability to address malnutrition and improve optimal human development [12]. Furthermore, Gillespie, addresses the role of politics to reduce malnutrition and argues that undernutrition is a multisectoral challenge [13].

Government policies and programs are tools for measuring nutrition governance and the commitment to reducing malnutrition at the national level [14]. These policies and programs affect the immediate, basic, and underlying determinants of nutrition identified by UNICEF [15]. For example, food policies and programs ensure that food system activities are directed to improve dietary intake and nutrition outcomes. The United States of America's farm bill for example make provision for food stamps, nutrition, and regulation of food markets. The integrated nutrition policy of South Africa for example, covers wider issues such as food production, access to water, sanitation, and healthcare [16, 17], In low- and middle-income countries nutrition policy analysis is limited. To fill this gap, this study was conducted to examine food and nutrition security policies in Eswatini.

Consequently, improving food and nutrition security will require decisive action, policies, and programs that address the multiple, complex determinants of malnutrition. To reduce obesity in Brazil, the government implemented the sugar tax [18]. This policy led to significant reductions in the intake of sugar-sweetened beverages. Although inconclusive, the provision of social grants has contributed to reducing the burden of food insecurity in most deprived households in South Africa [19, 20]. Yet, the role of policies in shaping and preventing risk are complex and poorly understood [21,22]. Nutrition policy is not prioritized in most city government mandates [23]. In addition, multisectoral response to food and nutrition insecurity is lacking and multisectoral policy initiatives are hindered by a lack of political will and resources [17, 24]. Coordination, administration and implementation of policies is usually within a ministry with limited input from other ministries or stakeholders [25]. According to a report by the World Health Organization (WHO), Given the potential of policy to reduce the risk of food insecurity and malnutrition, it is essential to understand how food and nutrition security is governed in Eswatini. This paper presents an analysis of food and nutrition security policies in Eswatini by examining: (1) the actors involved in policy making (2) the strength of nutrition governance, (3) the nutrition-specific and sensitive initiatives provided through policies and (4) multisectoral action on food and nutrition security. The findings are essential for tracking efforts towards achieving global nutrition targets. multisectoral policy initiatives are hindered by a lack of political will and resources [26].

\section{Food and nutrition security trends in Eswatini}

The Kingdom of Eswatini (formally known as Swaziland) is a landlocked country in Southern Africa. About 1.14 million people lived in the country in 2018 [27]. Although the country is classified as a lower middleincome country, the poverty rate is high and about a third of the population live below the national poverty line [28] In Eswatini food and nutrition insecurity are major public health problems. About one-fourth of Swazi's were dependent on food aid in 2011 [28]. Yet, about $6 \%$ of men and $17 \%$ of women are obese [29]. This challenge is compounded by a high rate of HIV/AIDS [30]. A study conducted in Eswatini found that food insecurity is associated with risky lifestyle and sexual behaviors, leading to an increased risk for HIV transmission and subsequently worsening in the living conditions of the ordinary Swazi [24]. Food insecurity affects social relationships negatively. In Eswatini some, food insecure women were more likely to use alcohol, practice inconsistent condom use with a nonprimary partner, engage in sex exchange, and intergenerational sexual relationships [31,32].

The experience of poverty is entrenched in rural areas where about $79 \%$ of the population live [27]. Compared to urban areas, income in rural areas is four times lower. Eswatini has land and water resources with a favourable climate for the production of crops and livestock. The country is divided into four agro-ecological zones: the Highveld (high rainfall), the Middleveld (medium rainfall), the Lowveld (low rainfall) and the Lubombo plateau [33]. National main livelihoods includes formal labour $18 \%$, remittances $17 \%$, small business $14 \%$, food crop production $12 \%$, social grants $11 \%$ and casual labour $11 \%$ [34].

Eswatini just like South Africa, is experiencing a dietary transition. Between 1800 and 1871, subsistence farming and hunting were the predominant mode of acquiring food. The meals consisted of a blend of indigenous plants, fruits, seeds and vegetables [35]. In 1871, the country was colonised by the United Kingdom. New food items were introduced into the Swazi diet during the period. In addition, food stores were introduced which also facilitated the acquisition of the new food items. These food items included baked wheat flour products, rice, fish and chips, canned foods, fruits, vegetables, and sugar products [36]. These products changed the food culture of the people. 
For example, breakfast meal changed from soft porridge (fresh or fermented) to bread and tea; and Sunday lunch to rice, chicken, salads, and cooked vegetables [35]. The introduction of shops also influenced the Swazi eating pattern and meals shifted from 2 to 3 main meals with snacks in-between [36]. Cooking forms also changed and the use of soup powders and frying, stewing, grilling, steaming, baking, and the blending of more than one cooking methods was adopted by the Swazis [37]. With the development of industry and the service sector, some of the residents moved from rural to urban areas. The urban population depends on convenient foods and eating out daily is becoming a normal practice.

Agricultural productivity in Eswatini is low due to recurring drought, chronic underinvestment and the impact of HIV/AIDS [33]. Yet, $70 \%$ of the population are farmers. Between 2014 and 2016, the country was affected by a severe drought and a Fall Army Worm invasion that affected crops such as maize, sorghum, soybeans, groundnuts, and potatoes, and worsened agricultural productivity [38]. In 2016 about $80 \%$ of cereal was imported. This led to an increase in the price of maize, even though the price had been falling in the Southern Africa region. The price of maize meal was more expensive in Swaziland in 2019 (USD283) compared to South Africa (USD153) [39], and this had an impact on the consumer purchasing power affecting the value of remittances from Swazis living abroad. In 2011, the World Bank reported that households affected by HIV/AIDS reported a $54 \%$ reduction in maize production and cultivated $34 \%$ less land area.

In Swaziland, there are two types of land tenure namely land held in customary tenure, or Swazi Nation land (SNL) and land held by freehold tenure, or title deed land (TDL). About $40 \%$ of the country's land is classified as Title Deed Land (TDL), these are mainly used for commercial and large-scale farming. The farms produce, sugar cane and citrus, and rural residents are employed as farmworkers on these farms [40]. The remaining $60 \%$ is classified as SNL. The SNL lands are held in trust by the King and administered by local chiefs. The SNL lands are used by smallholder farmers who mainly produce maize. Out of the population involved in agriculture, $70 \%$ are smallholder farmers and occupy $75 \%$ of the arable land [41]. Smallholder farmers contribute only $11 \%$ of total agricultural output with cereal yields at a low average rate of 1.1 tonnes per hectare, even though these farms serve as the livelihood base for the rural population [33].

The 2019 Annual Vulnerability Assessment and Analysis (VAA 2019) for the $2019 / 20$ period included an evaluation of key sectors such as agriculture, health, nutrition, and education. This annual assessment reported that more than $20 \%$ of the rural Swazis population had experienced severe acute food insecurity, with $14.2 \%$ of Swazis indicating that in the past months they had faced moderate hunger whilst $8.5 \%$ were faced with severe hunger. Dietary patterns show a high reliance on maize and other starches, but low consumption of fruits, vegetables, milk, and meat. Household diet diversity had deteriorated and $23 \%$ of the population perceived that they do not have acceptable diets [42]. Almost all Swazi's do not meet the daily recommendation for fruits and vegetable intake. About 92\% (86\% for women and 93\% for men) do not eat 5 servings of fruits and vegetables daily [43]. A fifth of the population always add salt to food at the table as well as consume processed foods high in salt. In 2009, about $18 \%$ of households were food insecure [44]. This figure is on the increase, as the VAA 2019 projected that between October 2019 and March 2020, around 25\% of the rural population are estimated to experience severe acute food insecurity during the lean season [45]. There is a need to ensure good governance and multisectoral coordination across the different sectors of government to address these issues and build a functional and resilient food and nutrition system.

\section{Methodology \\ Study design}

This study employed a content analysis of policy documents. The methodology entailed exploration of deep understanding of the multi-sectoral approach used to implement food and nutrition interventions from the Ministry of Agriculture (MoA), Ministry of Education and Training (MoET), Ministry of Natural Resources and Energy (MoNRE) and Ministry of Health $(\mathrm{MoH})$. The key sector ministries policies, strategic plans, and annual reports were reviewed in terms of effective participation in ensuring functionality in the coordination of multi-sectoral or intersectoral actions. The policies and strategic plans were documents in existing governance structures. The study examined the multisectoral or intersectoral coordination effectiveness through analyses of annual reports. We decided to use annual reports instead of in-depth interviews since these reports are usually prepared by a team from each of the units within a ministry. Also, these documents are recorded histories of activities of the past year and do reflect precisely what the institutions did, instead of what they had hoped to do.

\section{Source of data}

We used a policy analysis framework to examine the implementation and impact of existing policies. A search of public policies, annual reports, and minutes of board meetings of the Ministry of Agriculture (MoA), Ministry of Education and Training (MET), Ministry of Natural Resources and Energy (MoNRE) and Ministry of Health 
$(\mathrm{MoH})$ from 2015-2019 was conducted. These ministries are the recognized government lead actors in food and nutrition security programs. The strategies, and policies from the ministries were searched through Google and ministerial websites. The documents that could not be retrieved through online searches were retrieved through appointments. In each of the ministries, appointments were made with planning officers through the Principal Secretary's office to authorize the release of such documents. The government established the Swaziland National Nutrition Council (SNNC) in 1945 in the Ministry of Health. The council is responsible for advocacy, coordination and strategic guidance on nutrition within the country [46]. Due to the strategic influence of the council on nutrition in the country, we requested for their annual reports and the minutes of the council board meetings.

\section{Data analysis}

The analysis begun by reading the identified documents. To examine the strength of nutrition governance in Eswatini, we adopted the nutrition governance indicator developed by the WHO [47]. The nutrition governance indicator is a composite variable with ten elements: Existence of intersectoral mechanism to address nutrition; Existence of national nutrition plan or strategy; Adoption of national nutrition plan or strategy; Whether national nutrition plan or strategy is part of national development plan; Existence of national nutrition policy; Existence of national dietary guidelines; Allocation of budget for implementation of national nutrition plan, strategy or policy; Implementation/existence of regular nutrition monitoring and surveillance and Existence of budget-line for nutrition in health budget. For each of these elements a score of 1 was given if present, 0 if otherwise. A total score of 10 signifies strong nutrition governance, 8-7 medium nutrition governance and 6-0 weak nutrition governance [48]. We used the WHO framework because the set of indicators were identified by policy makers from different countries themselves. The indicators were also seen as crucial for successful development and implementation, and for determining the completeness of national nutrition policies and strategies.

To assess the interventions provided by the government, we searched for nutrition-sensitive and nutritionspecific programs in the policies. Nutrition-sensitive interventions or programs were defined as those that address the underlying determinants of fetal and child nutrition and development, such as agriculture, social protection, child protection, water and sanitation, classroom education [49]. Nutrition-specific interventions or programs were defined as those that address the immediate determinants of fetal and child nutrition and development-adequate food and nutrient intake, feeding, caregiving and parenting practices, and low burden of infectious diseases [49].

In order to examine multisectoral and intersectoral policy actions we analyzed the annual and quarterly reports of the selected ministries. Multisectoral coordination was defined as the deliberate collaboration among various stakeholders and sectors to jointly achieve a policy outcome. We used key words that were identified as barriers or enablers to multisectoral action from the WHO report on multisectoral action for improved health [26]. These keywords were engage/ment, exchange, communication, exchange, collaboration, coherence, capacity, commitment and political will. A word search was conducted for each of these words in the documents. We thematically analyzed the context within which these words were used.

\section{Results \\ Food and nutrition security policies in Swaziland Documents included in the review}

The documents reviewed were policy documents from the five government ministries. The Public Policy Coordinating Unit of the Prime Minister's Office had guided the development of each policy. The nine policy documents were developed from 2005 to 2019 (Table 1). Furthermore, it was possible to retrieve 5 annual reports from the nutrition council and four of the minutes of the council's board meetings.

The National Food Security Policy of 2005 was developed through consultant engagement [50]. The process was led by the Public Policy Coordination Unit. The goal of this policy was to ensure that, 'all people in Swaziland at all times, have physical and economic access to sufficient, safe and nutritious food to meet their dietary needs and food preferences for an active and healthy life'(p.10) [50]. The goal was formulated in line with the four pillars of food security: availability, accessibility, utilization and stability.

In 2016, the National Health Sector Policy was developed with stakeholders from the Ministry of Health, other government ministries, non-governmental organization in the health sector (Ministry of Health, 2016). Financial support of the process was provided by the WHO. In developing the Education and Training Sector Policy, the Ministry of Education was supported by UNICEF both technically and financially. A consultant was engaged to draft the policy, the Ministry facilitated the review process through consultation meetings with the education sector partners and stakeholders [51]. The National Water Policy was developed through a similar consultative process, a task team was set-up with key actors from the government ministries, UN Agencies, 
Table 1 Summary of policy review

\begin{tabular}{|c|c|c|c|}
\hline Responsible department & Document name & Year enacted & Associated programs \\
\hline Ministry of Agriculture (MoA) & Food Security Policy & 2005 & $\begin{array}{l}\text { Food production } \\
\text { Dietary diversification } \\
\text { Food aid } \\
\text { Micronutrient deficiency } \\
\text { Nutrition in control, prevention, and treatment } \\
\text { of diseases } \\
\text { HIV/AIDS impact mitigation } \\
\text { Food hygiene }\end{array}$ \\
\hline \multirow[t]{3}{*}{ Ministry of Health $(\mathrm{MoH})$} & National Health Sector Policy & 2016 & $\begin{array}{l}\text { Integrated child health services } \\
\text { Viral load suppression } \\
\text { Prevention of mother to child } \\
\text { Transmission } \\
\text { Immunization, }\end{array}$ \\
\hline & Food and Nutrition Policy & 2016 & $\begin{array}{l}\text { Integrated Management of Acute Malnutrition } \\
\text { Maternal and child health } \\
\text { National infant feeding programme Expanded } \\
\text { programmes for immunization Supplemen- } \\
\text { tary feeding programme } \\
\text { Integrated management of childhood illness } \\
\text { Integrated growth monitoring, } \\
\text { Nutrition and communicable and noncommu- } \\
\text { nicable diseases }\end{array}$ \\
\hline & Sanitation and Hygiene Policy & 2019 & $\begin{array}{l}\text { Hand washing, personal hygiene and safe use of } \\
\text { water hygiene programme } \\
\text { Environmental health services }\end{array}$ \\
\hline \multirow[t]{2}{*}{ Ministry of Education and Training (MoET) } & Education and Training Sector Policy & 2018 & Nutritional support programmes \\
\hline & Food Security Policy in Schools & 2013 & School feeding programmes \\
\hline $\begin{array}{l}\text { Ministry of Natural Resources and Energy } \\
\text { (MoNRE) }\end{array}$ & National Water Policy & 2017 & Rain-fed agricultural production \\
\hline
\end{tabular}

Non-Governmental Organization, and International Non-Governmental Organizations [52].

\section{Actors involved in policy-making and their roles}

Five actor groups were identified namely: government ministries, national academic institutions, United Nations agencies and, bilateral organizations. These actors supported food and nutrition security policy through funding, technical support, and capacity building. A 2011 Food and Agricultural Organization Evaluation document describes 'The African Development Bank, United Nations (UN) agencies, the United States, and the European Commission as the major donors of general development activities' in Eswatini (p.17) [53].

Table 2 Eswatini nutrition governance summary

\begin{tabular}{|c|c|c|}
\hline Element of nutrition governance & Status in Eswatini & Evidence \\
\hline Existence of an intersectoral mechanism to address nutrition & Present & National Nutrition Council, established in 1945 \\
\hline Existence of a national nutrition plan or strategy & Present & Swaziland National Plan of Action for Nutrition \\
\hline Adoption of the national nutrition plan or strategy & Present & The national plan was adopted in 1996 \\
\hline $\begin{array}{l}\text { Inclusion of the national nutrition plan or strategy as part of } \\
\text { the national development }\end{array}$ & Present & $\begin{array}{l}\text { The nutrition plan is included in the National Strategy for Sus- } \\
\text { tainable Development \& Inclusive Growth 2017-2030 }\end{array}$ \\
\hline Existence of a national nutrition policy & Present & National Food and Nutrition Policy, 2016 \\
\hline Adoption of the national nutrition policy & Absent & The policy is still a draft \\
\hline Existence of national dietary guidelines & Absent & \\
\hline $\begin{array}{l}\text { Allocation of budget for implementation of the national nutri- } \\
\text { tion plan, strategy or policy }\end{array}$ & Present & $\begin{array}{l}\text { Fund are allocated to health and agriculture sectors for nutrition } \\
\text { policy }\end{array}$ \\
\hline Regular nutrition monitoring and surveillance & Present & The government organise regular surveys \\
\hline Existence of a line item for nutrition in the health budget & Present & The Ministry of Health has a nutrition line item for nutrition \\
\hline
\end{tabular}


The European Union (EU) for example, provided funding for sector interventions, such as agriculture, water, governance, health and education. In 2016, the Taiwanese Government supported infrastructure projects [54]. Through the Global Fund, the United Nations has provided funding for health and gender programs, HIV/ AIDS treatment and prevention, and statistics and poverty reduction activities in the country [55]. Between 2001 and 2019, the USAID had provided about \$24 million to all government agencies in Eswatini. The funds were mainly towards household surveys and disease surveillance [56].

The food and nutrition security actors have also been providing technical support to the Eswatini government in delivering its objectives. In particular, the United States President's Emergency Plan for AIDS Relief (PEPFAR) has assisted the Ministry of Health with report writing and policy development initiatives. In addition, the Institute for Health Measurement (IHM) Southern Africa has been instrumental in providing health system performance reviews and program reviews for child health, HIV/AIDS and non-communicable diseases [57]. This acknowledgment made by the ministry of health in their 2015 NCD program report depicts the actions of some policy actors "During the period under review, the Unit implemented a number of human resource activities within the four thematic areas; planning, management, development and research with financial support from PEPFAR and technical support from its major implementing partner, the World Health Organisation (WHO)" [58](p.6).

\section{The strength of nutrition governance in Eswatini}

The WHO has provided a guideline for assessing the strength of nutrition governance of countries [47]. The status of readiness of Eswatini to accelerate nutrition programs was assessed using the ten elements and is presented in Table 2. The landscape analysis indicates that the country is prioritizing nutrition in its development strategies. This is evident through the establishment of the Swaziland National Nutrition Council (SNNC) by an Act of Parliament in 1945, the inclusion of the United Nations Development Assistance Framework (UNDAF) in the National Development Strategy, and the conduct of regular nutrition surveillance.

However, the country did not meet all the criteria stipulated. Firstly, the recent national food and nutrition policy has not been adopted. In 2017, the Ministry of Health was unable to present the policy to parliament for adoption. In addition, the country has no dietary guidelines for its citizens. Therefore, with a total score of 8, the country can be classified as having a medium-strength nutrition governance.

\section{Nutrition sensitive and nutrition specific interventions provided by the Eswatini government}

The nutrition-specific programs implemented by Eswatini government included: micronutrient supplementation and deworming programs, breastfeeding campaigns, and treatment of acute malnutrition (Additional file 1). The nutrition-sensitive initiatives included programs on school nutrition, sanitation and hygiene, agriculture production, and healthcare. For each of these programs, the impact was low due to limited budgets, low coverage, and mismanagement of funds. This statement is supported by the following example, between 2016 and 2017, the number of clients receiving therapeutic feeding under the Food by Prescription Programmed reduced from 2907 to 2000 [59]. Therefore, the World Food Program (WFP) adopted the Food by Prescription Program in 2018 [60]. Likewise, the only 65\% of children aged 1-18 years and pregnant women were provided with Albendazole in 2018. Similarly, the WFP considered the school nutrition program as inefficient due to the low quality of meals but the high cost of the program per child [61].

\section{Multisectoral coordination of policies}

The word capacity dominated in all the annual reports throughout the period under review. The word was used to highlight initiatives as well as limitations. Capacity actions were mainly to facilitate vertical coordination. Capacity building programs were delivered through workshops and training sessions for national, regional, and local project teams to better execute their roles. In a few cases, staffs were expected to further their education to the honors and master's levels. Some of the staff registered for masters in planning, management, budgeting, computing, and curriculum development. The planning unit of the $\mathrm{MoH}$ in 2014 for example, was able to conduct three quarterly meetings per region with the Regional Health Management Teams (RHMT). The purpose of these meetings was to enhance accountability and ownership of the $\mathrm{MoH}$ activities at regional level by the RHMTs. In these meetings, RHMTs were able to present their budget for 2013/14 to the $\mathrm{MoH}$ senior officials, taught the new budgeting system, share their annual plans and progress made on the annual work plans [62] (p.21). Some ministries were also involved in capacity-building programs for community stakeholders. The goal of such capacity-building programs was to aid the community stakeholders to better support the implementation of specific objectives. Capacity was also used to highlight limitations. It was used also to describe the shortage of staffs, and technical skills. 
The words engage, coordination, communication, collaboration, and exchange were used to examine vertical and horizontal networking activities with stakeholders. The activities took two main spheres, implementation of projects and employment. The ministries reported engaging expert consultants and contractors to help deliver project activities. The experts were employed for activities such as ploughing and computing [63].

The ministries were involved in several projects such as the Mnyngombili and Tsambokulu Potable Water Scheme, Health and Nutrition Project, Literacy Boost Project, Micro Project to Rehabilitate Schools and Smallholder Market Led Project [62, 63]. The projects were being implemented in collaboration with officers from partner organizations. Some of the collaborators of the MoA for example, included the University of Eswatini, Swaziland Standards Authority, Taiwan government, Eswatini Standards Authority [41].

Despite all these initiatives, coordination activities will require attention and resources. In particular personnel from the lead departments to initiate, maintain and monitor such activities was inadequate. The MoET noted this challenge in their 2015 annual report, "Not enough personnel in the department, there is only ONE officer to coordinate and manage all the activities of the department. The shortage of personnel limits the number schools/learning institutions that can be inspected and it also affects monitoring of the feeding programme", (p.38) [63].

The words commitment and political will were used as indicators of program sustainability. In most of the annual reports, the ministries reported commitment to service delivery and core values. There was also commitment from partners. UNICEF for example committed to provide the MoET with expertise in computing to aid the school feeding program [63]. Cabinet's commitment is indicated by the budget allocation for the policy programs. These resources can be used to strengthen strategic, operational and technical capacities at all levels. However, the level of financial commitment is suboptimal. In as much as the planning documents had the political will, these commitments were untracked during implementation.

\section{Discussion and conclusion}

The role of governance in addressing food and nutrition security is complex and difficult to understand. This study examined the governance of food and nutrition security in Eswatini using policy documents. The findings show that diverse actors are involved in policymaking in Eswatini. In addition, the strength of nutrition governance was medium. Furthermore, the nature of multisectoral coordination was ad-hoc. Our findings confirm what other research has suggested for years: nutrition governance is weak in low and middle-income countries $[2,48,64]$. This section provides an explanation of the findings and its implication for achieving food and nutrition security in the country.

The strength of nutrition governance in Eswatini was medium. This is similar to countries in the Southern African region such as Madagascar, Zambia and South Africa but lower than Malawi when these countries were examined in 2008/2009 [65]. This suggest that progress on nutrition governance in Eswatini is slow and not in line with the WHO set of indicators for strong nutrition governance [47]. In particular, the absence of a national dietary guideline can limit the ability of practitioners to provide context-specific advice on healthy diets and lifestyles [66]. The country's nutrition-specific objectives are similar to the Lancet Series objectives, but have additional objectives like; prevention of malnutrition by supplementary feeding and other activities for children and people with special needs and NCD programs.

Due to the multisectoral nature of nutrition, attention, and action from a wide range of actors is always required. Therefore, multi-stakeholder partnerships have been regarded as a good governance indicator [67]. The diverse team of actors involved in policymaking in Eswatini as shown by the findings can enable a more inclusive framing of existing challenges and encourags shared ownership programs [68-70]. However, there was an absence of engagement with the private sector, especially the food retail industries. Yet, such industries are penetrating the market and this can have implications for food and nutrition security. In 2017, about 10 Shoprite stores, as well as Usave, Ok franchise and Hungry Lion were operating in the country [71]. Supermarket expansion has been associated with the weakening of the informal food market and the introduction of high fat, sugar, and salty foods globally [72, 73].

In the context of Eswatini the findings show that ministries are working together, but there is a missing character to make the benefits sustainable. The findings indicate that ad-hoc collaboration is the common practice during horizontal policy implementation. Ministries were collaborating with other stakeholders through temporary projects and the hiring of expert consultants. These forms of networking are informal, there is no continuity, monitoring of the impact of interventions implemented in such partnership can be problematic [26]. The lack of documentation of learnings, best practices, and failures to inform future interventions, makes partners not fully enjoy the investment of working together. 


\section{Strengths and limitations}

To the best of our knowledge, this study is the first of its kind to examine food and nutrition security policies in Eswatini. The findings provide an understanding of the diverse policy actors in Eswatini, the strength of nutrition governance, actors involved in policymaking and implementation, and challenges with multisectoral coordination. However, the sole reliance on desk literature minimized the ability to interview key stakeholders, whose perspective could have enriched the findings. Future research can interview the actors identified by this study.

\section{Conclusion}

Our study suggests that although the government of Eswatini has provided initiatives to address food and nutrition security, the governance strength is medium, some of the programs are ineffective and inefficient, and horizontal multisectoral coordination is inconsistent. In terms of practice, we recommend the inclusion of the private sector in policy processes and a structured approach in engaging other stakeholders. To further clarify the impact of policy processes on nutrition and food security, future studies can include key informant interviews. These in-depth interviews can focus on the policy process; knowledge management, advocacy, implementation, monitoring and evaluation of nutrition programs by these actors. Equally important will be studies to determine budget allocations and expenditure after the adoption of the sustainable development goals.

\section{Supplementary Information}

The online version contains supplementary material available at https://doi. org/10.1186/s40066-021-00307-8.

Additional file 1. Nutrition sensitive and nutrition specific interventions provided by the Eswatini government.

\section{Acknowledgements}

Not applicable

\section{Authors' contributions}

All authors contributed to the study's conception and design. Material preparation, data collection, and analysis were performed by Thobile Phungwayo.

The first draft of the manuscript was written by Sandra Boatemaa Kushitor and all authors commented on previous versions of the manuscript. Thobile Phungwayo was supervised by Sandra Boatemaa Kushitor and Liesbet Koornhof. All authors read and approved the final manuscript.

\section{Funding}

No funds, grants, or other support was received.

\section{Availability of data and materials}

The policy documents used in this study have been presented in Table 1. They can be retrieved from the respective government ministries' websites.

\section{Declarations}

Ethics approval and consent to participate

Not applicable.

\section{Consent for publication}

Not applicable.

\section{Competing interests}

The authors declare that they have no competing interests.

\section{Author details}

${ }^{1}$ WaterAid Country Program, Mbabane, Eswatini. ${ }^{2}$ Food Security Initiative and Centre for Complex Systems in Transition, Stellenbosch University, Stellenbosch, South Africa. ${ }^{3}$ Department of Human Nutrition, Stellenbosch University, Stellenbosch, South Africa.

Received: 1 December 2020 Accepted: 3 May 2021

Published online: 14 October 2021

\section{References}

1. Willett W, Rockström J, Loken B, Springmann M, Lang T, Vermeulen S, et al. Food in the anthropocene: the EAT-lancet commission on healthy diets from sustainable food systems. Lancet. 2019;6736(18):3-49.

2. Von GK, Bernstein J, Hossain N, Brown T, Prasai N, Yohannes Y, et al. 2017 Global Hunger Index: The Inequalities of Hunger. International Food Policy Research Institute: Washington; 2017.

3. Garrett JL. Achieving urban food and nutrition security in the developing world. 2002. http://www.fao.org/fileadmin/templates/ags/docs/MUFN/ DOCUMENTS/IFPRI_focus03.pdf. Accessed 20 Dec 2019

4. IFPRI. Global nutrition report 2018 [Internet]. New York; 2019. https:// globalnutritionreport.org/reports/global-nutrition-report-2018/.Accessed 6 Jun 2019

5. Naghavi M, Forouzanfar MH. Burden of non-communicable diseases in sub-Saharan Africa in 1990 and 2010: Global Burden of Diseases, Injuries, and Risk Factors Study 2010. Lancet. 2013;381:S95.

6. Perkins JM, Kim R, Krishna A, McGovern M, Aguayo VM, Subramanian SV. Understanding the association between stunting and child development in low- and middle-income countries: Next steps for research and intervention. Soc Sci Med. 2017;193:101-9. https://doi.org/10.1016/j. socscimed.2017.09.039.

7. Gakidou E, Afshin A, Abajobir AA, Abate KH, Abbafati C, Abbas KM, et al. Global, regional, and national comparative risk assessment of 84 behavioural, environmental and occupational, and metabolic risks or clusters of risks, 1990-2016: a systematic analysis for the Global Burden of Disease Study 2016. Lancet. 2017;390(10100):1345-422.

8. Tilman D, Clark M. Global diets link environmental sustainability and human health. Nature. 2014:515(7528):518-22.

9. Kumanyika S. Nutrition and chronic disease prevention: priorities for US Nutr Rev. 2006;64(2):9-14

10. IFPRI. 2020 Global nutrition report: action on equity to end malnutrition [Internet]. Bristol; 2020. https://globalnutritionreport.org/reports/2020global-nutrition-report/. Accessed 6 Jun 2019.

11. UNICEF. Improving child nutrition: the achievable imperative for global progress. New York: UNICEF; 2013.

12. Black RE, Victoria CG, Walker SP, Zulfiqar AB, Christian P, Onis M. Maternal and child undernutrition and overweight in low-income and middleincome countries. Lancet. 2013;382(9890):427-51.

13. Gillespie S, Haddad L, Mannar V, Menon P, Nisbett N, Maternal and Child Nutrition Study Group. The politics of reducing malnutrition: building commitment and accelerating impact. Lancet. 2013;382(9891):552-69.

14. Candel JJL. Food security governance: a systematic literature review. Food Sec. 2014. https://doi.org/10.1007/s12571-014-0364-2.

15. Termeer CJAM, Drimie S, Ingram J, Pereira L, Whittingham MJ. A diagnostic framework for food system governance arrangements: the case of South Africa. NJAS Wageningen J Life Sci. 2018;84:85-93. 
16. Drimie S, Ruysenaar S. The integrated food security strategy of south africa: an institutional analysis. Agric Econ Res Policy Pract South Africa. 2010;49(3):316-37.

17. Boatemaa S, Drimie S, Pereira LM. Addressing food and nutrition security in South Africa: a review of policy responses since 2002. African J Agric Resour Econ. 2018;13(3):264-79.

18. Claro RM, Levy BR, Popkin BM, Monteiro CA. Sugar-sweetened beverages taxes in Brazil. Am J Public Health. 2012. https://doi.org/10.2105/AJPH. 2011.300313

19. Devereux S. Social protection for enhanced food and nutrition security in Sub-Saharan Africa. Food Policy. 2016;60:52-62.

20. Devereux S, Waidler J. Why does malnutrition persist in South Africa despite social grants? Food security working paper series No. 001. Bellvile, South Africa; 2017. https://foodsecurity.ac.za/wp-content/uploads/2018/ 04/Final_Devereux-Waidler-2017-Social-grants-and-food-security-in-SA25-Jan-17.pdf.

21. International Food Policy Research Institute. 2018 Global food policy report. Washington: International Food Policy Research Institute; 2018.

22. Garret J, Kadiyala S, Kohli N. Working multisectorally to improve nutrition: global lessons and current status in India. New Delhi; 2014. http://ebrary. ifpri.org/utils/getfile/collection/p15738coll2/id/128091/filename/128302. pdf.

23. Freudenberg N, Atkinson S. Getting food policy on the mayoral table: a comparison of two election cycles in new york and London. Public Health. 2015;129(4):295-302. https://doi.org/10.1016/j.puhe.2015.02.018.

24. Harris J, Drimie S, Roopnariane T, Covic N. From coherence towards commitment: changes and challenges in Zambia's nutrition policy environment. Glob Food Sec. 2017. https://doi.org/10.1016/j.gfs.2017.02.006.

25. World Health Organization. Globak nutrition policy review: What does it mean to scale up nutrition action? Geneva: World Health Organization; 2013.

26. World Health Organization. Multisectoral and intersectoral action for improved health and well-being for all: mapping of the WHO European Region. Geneva: World Health Organization; 2018.

27. World Bank. Eswatini [Internet]. Country profile. 2018. https://databank. worldbank.org/views/reports/reportwidget.aspx?Report_Name=Count ryProfile\&ld=b450fd57\&tbar=y\&dd=y\&inf =n\&zm=n\&country=SWZ. Accessed 5 Feb 2020.

28. United Nations. Milleneum development goals report 2011. New York: United Nations; 2011.

29. Agyemang C, Boatemaa S, Agyemang G, de Graft Aikins A. Obesity in sub-Saharan Africa. In: Ahima R, editor. Metabolic syndrome. Cham: Springer International Publishing; 2015. p. 41-53.

30. Baral S, Ketende S, Green JL, Chen PA, Grosso A, Sithole B, et al. Reconceptualizing the HIV epidemiology and prevention needs of female sex workers (FSW) in Swaziland. PLoS ONE. 2014;9(12):1-17.

31. Weiser SD, Leiter K, Bangsberg DR, Butler LM, Percy-De Korte F, Hlanze Z, et al. Food insufficiency is associated with high-risk sexual behavior among women in Botswana and Swaziland. PLoS Med. 2007;4(10):1589-98

32. Fielding-Miller R, Mnisi Z, Adams D, Baral S, Kennedy C. "There is hunger in my community": a qualitative study of food security as a cyclical force in sex work in Swaziland. BMC Public Health. 2014;14(1):1-10.

33. Bank W. Swaziland rural sector review [Internet]. 2011. https://openk nowledge.worldbank.org/bitstream/handle/10986/12770/702000ESW0 P11900PN100June0270020110.pdf? sequence=1. Accessed 6 Jun 2019.

34. UNICEF. Social assistance budget brief for Kingdom of Eswatini. Newyork: UNICEF; 2017

35. Kgaphola MS, Viljoen AT. Food habits of rural Swazi households: part 2: social structural and ideological influences on Swazi food habits. J Fam Ecol Consum Sci. 2004;32:16-25.

36. Kgaphola MS, Viljoen AT. Food habits of rural Swzi households: 1939-1999 Part 1: technological influences on Swazi food habits. Tydskr vir Gesinsekologie en Verbruikerwetenskappe. 2000;28:68-74.

37. Huss-Ashmore R, Curry J. Diet, nutrition, and agricultural development in Swaziland 3 Household economics and demography. Ecol Food Nutr. 1994. https://doi.org/10.1080/03670244.1994.9991419.

38. SADC. Swaziland: Vulnerability assessment committee results 2017 [Internet]. Mbabane; 2017. https://reliefweb.int/sites/reliefweb.int/files/resou rces/sadc_swaziland_2017_0.pdf. Accessed 6 Jun 2019.
39. FAO. Eswatini increases maize prices [Internet]. Food price monitoring and analysis. 2019. http://www.fao.org/giews/food-prices/food-policies/ detail/en/c/1201438/. Accessed 8 Feb 2021.

40. Amnesty International. "They dont see us as people", Security of tenure and forced evictions in Estwatini [Internet]. London; 2018. https://www. amnesty.org/download/Documents/AFR5587852018ENGLISH.PDF. Accessed 6 Jun 2019

41. Ministry of Agriculture. Annual perfomance report 2018-2019. Mbabane: Ministry of Agriculture; 2019.

42. SADC. Swaziland: Vulnerabilit assessment report 2019. Gaborone: SADC; 2019.

43. Ministry of Health. Annual non-communicable diseases (NCD) program report. Mbabane: Ministry of Health; 2016.

44. World Bank. Nutrition at a glance, Swaziland [Internet]. 2010. http:// documents1.worldbank.org/curated/en/228251468123864930/pdf/ 771980BRI0Box00swaziland0April02011.pdf. Accessed 6 Jun 2019.

45. SADC. Swaziland annual vulnerability assessment and analysis report 2019 [Internet]. Mbabane; 2019. https://reliefweb.int/sites/reliefweb.int/ files/resources/2019\%20ESWATINI\%20VAC\%20REPORT.pdf. Accessed 6 Jun 2019.

46. FAO. Country nutrition paper [Internet]. Rome; 2014. http://www.fao. org/3/at628e/at628e.pdf. Accessed 6 Jun 2019.

47. World Health Organization. Nutrition landscape information system: country profile interpretation guide. Geneva: World Health Organization; 2010.

48. Engesveen K, Nishida C, Prudhon C, Shrimpton R. Assessing countries' commitment to accelerate nutrition action demonstrated in PRSPS, UNDAFs and through nutrition governance. Vol. 37, SCN News. pp.10-16 2009.

49. Ruel MT, Alderman $\mathrm{H}$. Nutrition-sensitive interventions and programmes: how can they help to accelerate progress in improving maternal and child nutrition? Lancet. 2013;382:536-51.

50. Ministry of Agriculture. National food security policy for Swaziland. Mbabane: Ministry of Agriculture; 2005.

51. Ministry of Education and Training. The Swaziland education and training sector policy [Internet]. Mbabane; 2011. http://www.snat.org.sz/New\% 20Page/The\%20Education\%20Sector\%20Policy.pdf. Accessed 6 Jun 2019.

52. Ministry of Natural Resources and Energy. National water policy [Internet] Mbabane; 2017. http://portal.unesco.org/en/files/47381/1267103655 1National_Water_Policy___Final_Draft_June_2009.doc/National\%2BWat er\%2BPolicy\%2B-\%2BFinal\%2BDraft_June\%2B2009.doc\#: :text=The\% 20Swaziland\%20National\%20Water\%20Policy,poverty\%20eradication\% 20and\%20economic\%20prosperity. Accessed 6 Jun 2019.

53. FAO. Swaziland agricultural development program [Internet]. Rome; 2011 http://www.fao.org/3/ap602e/ap602e.pdf. Accessed 6 Jun 2019.

54. Nhlengethwa SB, Matchata GG, Musaba E, Chilonda P. Trends in public agriculture spending in Swaziland [Internet]. Pretoria; 2014. http://ebrary. ifpri.org/utils/getfile/collection/p15738coll2/id/128931/filename/129142. pdf. Accessed 6 Jun 2019.

55. The Global Fund Data Explorer. Investsments HIV Estwatini [Internet]. 2019. https://data.theglobalfund.org/investments/home/-/HIV. Accessed 27 Nov 2019.

56. USAID. U.S. foreign aid by country: Eswatini [Internet]. 2019. https://explo rer.usaid.gov/cd/SWZ?fiscal_year $=2019 \&$ implementing_agency_id $=5 \&$ measure=Obligations. Accessed 15 Nov 2019.

57. Institute for Health Measurement (IHM) Southern Africa. Regional health performance report [Internet]. Pretoria; 2016. http://www.mneswazila nd.com/downloads/2015\%20Ministry\%20of\%20Health\%20Reports/ Annual\%20Regional\%20Manzini\%20Health\%20Performance\%20Report. pdf. Accessed 6 Jun 2019

58. Ministry of Health. First quarter report for 2019-20. Mbabane: Ministry of Health;

59. Swaziland National Nutrition Council. Annual program progress report, 2017. Mbabane: Swaziland National Nutrition Council; 2017.

60. WFP. WFP Swaziland country brief, January 2018 [Internet]. 2018. https:// reliefweb.int/report/swaziland/wfp-swaziland-country-brief-january2018. Accessed 6 Jun 2019.

61. The Evaluation Team. Decentralised evaluation: Evaluation of the national school feeding program in Eswatini 2010-2018 [Internet]. Mbabane; 2019. https://docs.wfp.org/api/documents/WFP-0000110837/downl 
$\mathrm{oad} /$ ?_ga $=2.212812823 .2000370550 .1575451983-1313861111.15754$ 51983. Accessed 6 Jun 2019

62. Ministry of Health. Annual performance report 2013/2014. Mbabane: Ministry of Health; 2014.

63. Ministry of Education and Training. Annual performance report 2014-2015. Mbabane: Ministry of Education and Training; 2015.

64. Webb P, Ghosh S, Shrestha R, Namirembe G, Gurung S, Sapkota D, et al. Measuring nutrition governance: an analysis of commitment capability, and collaboration in Nepal. Food Nutr Bull. 2016;37:170-82. https://doi. org/10.1177/0379572116674856.

65. Sunguya BF, Ong KIC, Dhakal S, Mlunde LB, Shibanuma A, Yasuoka J, et al. Strong nutrition governance is a key to addressing nutrition transition in low and middle-income countries: review of countries' nutrition policies. Nutr J. 2014;13(1):1-10.

66. FAO. Food-based dietary guidelines [Internet]. 2020. http://www.fao.org/ nutrition/education/food-dietary-guidelines/background/en/. Accessed 4 Nov 2020.

67. Jaskiewicz L, Dombrowski RD, Drummond HM, Barnett M, Mason M Welter C. Partnering with community institutions to increase access to healthful foods across municipalities. Prev Chronic Dis. 2013;10(3):1-10.

68. Grossman J, Webb K. Local food and nutrition policy. Aust J Public Health. 1991;15(4):271-6.
69. IPES-Food. What makes urban food policy happen? Insights from five cities. 2012. http://www.ipes-food.org/_img/upload/files/Cities_full.pdf. Accessed 6 Jun 2019.

70. Moragues A, Morgan K, Moschitz H, Neimane I, Nilsson H, Pinto M, et al. Urban food strategies: The rough guide to sustainable food systems. Foodlinks. 2013. https://orgprints.org/id/eprint/28860/1/foodlinksUrban_food_strategies.pdf. Accessed 6 Jun 2019.

71. Shoprite Holdings Limited. Integrated report 2017 [Internet]. 2017. https://www.shopriteholdings.co.za/content/dam/MediaPortal/docum ents/shoprite-holdings/integrated-report/2017/Shoprite_Holdings_IR_ 2017E_Full.pdf.

72. Crush J, Frayne B. Supermarket expansion and the informal food economy in Southern African cities: implications for urban food security. J South Afr Stud. 2011;37(4):781-807.

73. Campbell M. South African supermarket expansion in sub-Saharan Africa. Third World Themat A TWQ J. 2017;1 (5):709-25. https://doi.org/10.1080/ 23802014.2016.1327796.

\section{Publisher's Note}

Springer Nature remains neutral with regard to jurisdictional claims in published maps and institutional affiliations.
Ready to submit your research? Choose BMC and benefit from:

- fast, convenient online submission

- thorough peer review by experienced researchers in your field

- rapid publication on acceptance

- support for research data, including large and complex data types

- gold Open Access which fosters wider collaboration and increased citations

- maximum visibility for your research: over 100M website views per year

At BMC, research is always in progress.

Learn more biomedcentral.com/submissions 